\title{
Research Paper: Disregarded Health Problems of People With Disabilities: A Qualitative Study of Policymakers' Perspective
}

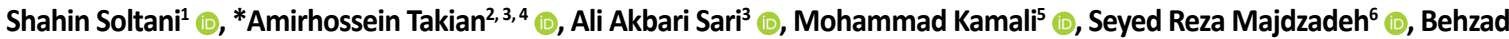 \\ Karami Matin ${ }^{1}$ (i)
}

1. Research Center for Environmental Determinants of Health (RCEDH), Kermanshah University of Medical Sciences, Kermanshah, Iran.

2. Department of Global Health \& Public Policy, School of Public Health, Tehran University of Medical Sciences, Tehran, Iran.

3. Department of Health Management and Economics, School of Public Health, Tehran University of Medical Sciences, Tehran, Iran

4. Health Equity Research Centre (HERC), Tehran University of Medical Sciences, Tehran, Iran.

5. Department of Rehabilitation Management, School of Rehabilitation Sciences, Iran University of Medical Sciences, Tehran, Iran.

6. Department of Epidemiology and Biostatistics, School of Public Health, Tehran University of Medical Sciences, Tehran, Iran.

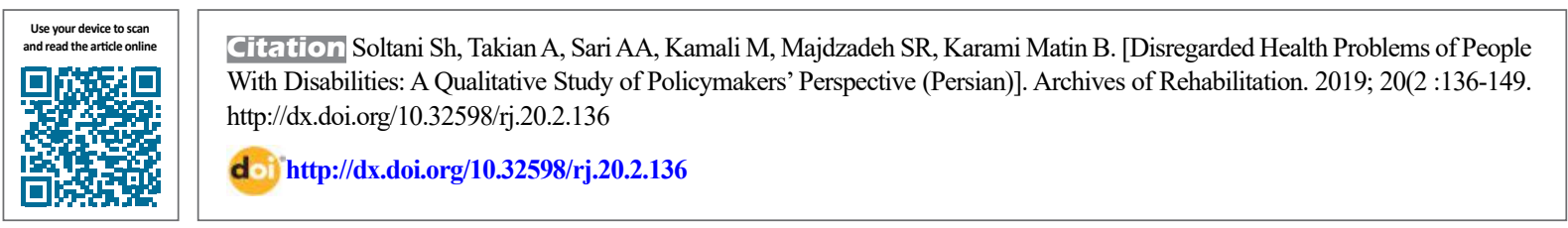

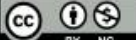

Received: 28 Nov 2018 Accepted: 10 Apr 2019 Available Online: $01 \mathrm{Jul} 2019$

Keywords:

Health policy, People with disability, Policy agenda, Influence, Iran

\section{A B STRACT}

Objective People with disabilities are more likely to experience poorer health status, compared to the general population; however, their health issues do not receive enough attention from policymakers. This article aimed to identify the factors that hinder the health problems of people with disabilities to be on the national agenda in Iran.

Materials \& Methods This phenomenological qualitative research was conducted in Tehran City, Iran, from September 2015 to March 2017. We conducted 22 quasi-structured face to face interviews with relevant policymakers at the national level. Snowball sampling method was applied to identify the interviewees. The interviewees were well-informed and had long and valuable experiences in the field of policymaking for people with disabilities. The policymakers from a verity of public organizations, ministries, nongovernmental organizations, Islamic Consultative Assembly, Tehran municipality and the health insurance organizations participated in the study. We used an interview guide in data collection process which covered the main study questions. On average, the interviews lasted about 30 minutes to 1.5 hours. The validity of the study was assessed through member checking. Thematic analysis was performed in three steps to identify the main concepts of the study. In open coding, identifying, naming and describing phenomena in the text were performed. Following open coding, codes were grouped into several subcategories. Then, the main concept of the study was created by formulating a general description of generated subcategories. We used MAXQDA to analyze the obtained data.

Results We found three main categories and 13 subcategories. In the influence category, three subcategories were created; low influence in the policy process, the lack of structural independence, the inferiority of associations and nongovernmental organizations' positions for policymakers and the low ability in lobbying and networking. In the minority category, we found 6 subcategories consisting of more attention to public health issues by policymakers, neglect of the specific needs of minority groups by health policymakers, policymakers' unattractiveness in the health problems of people with disabilities, the lack of significant financial and political benefits for policymakers, the lack of awareness about the health issues of people with disabilities, and the inferiority of disability issues for policymakers. In the category of lack of integrated voice, three subcategories were created, including a lack of integration among people with disabilities, inattention to personal and group interests and the lack of coherent communication networks. Conclusion To meet their requirements, it is essential to enhance the influence of people with disabilities, associations and the welfare organization in the policymaking process. This can be achieved by increasing the interaction of significant individuals in the disability area with other key policymakers in other sectors. Running campaigns, engaging with celebrities as well as experienced and influential managers, and the systematic use of media and social networks may improve policymakers' attention to prioritizing health issues of people with disabilities.

\section{* Corresponding Author:}

Amirhossein Takian, PhD.

Address: Department of Global Health \& Public Policy, School of Public Health, Tehran University of Medical Sciences, Tehran, Iran.

Tel: +98 (918) 3550106

E-Mail: takian@tums.ac.ir 


\title{
جرا مسائل سلامت افراد داراى ناتوانى در دستور كار سياست تخذاران قرار نمى تيرد؟: يك مطالعه كيفى از منظر سياست مكذاران سلامت دان
}

\author{
شاهين سلطانى'، "(مير حسين تكيان" ‘هrr، على اكبرى سارى"، محمد كمالى"، سيد رضا مجدزاده? بهزاد كرمى متين'

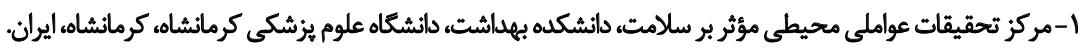

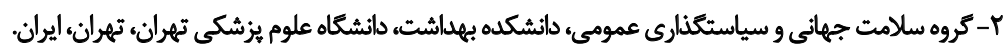

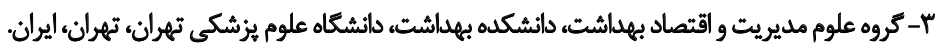

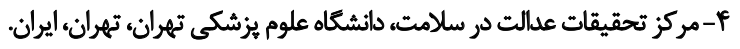

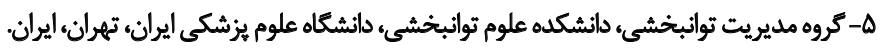

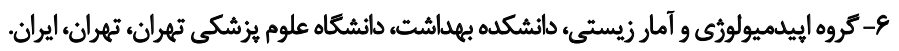

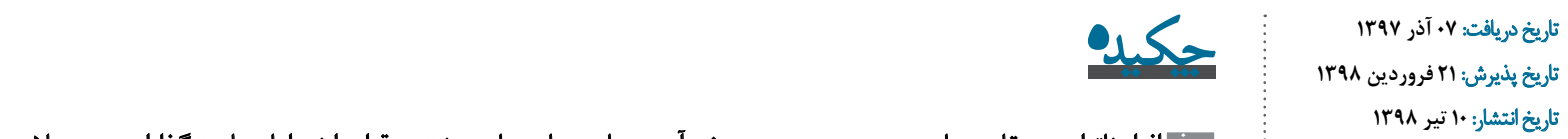

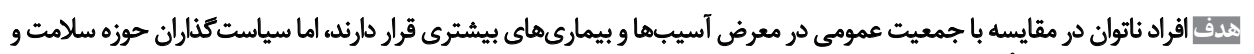

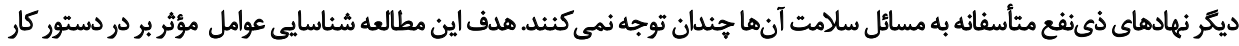

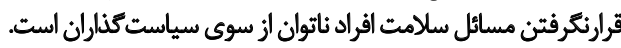

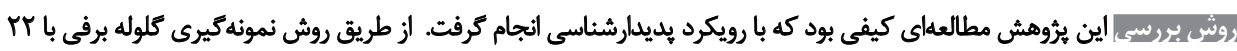

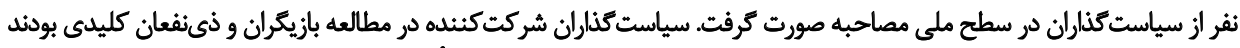

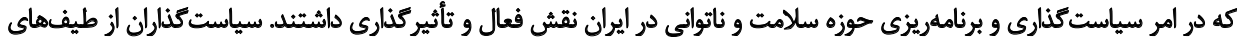

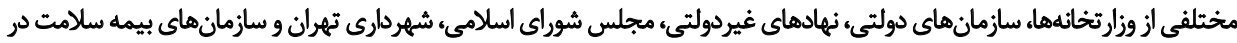

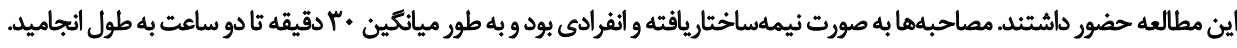

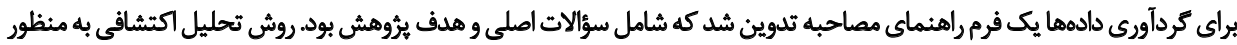

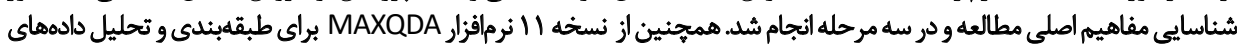

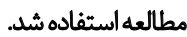

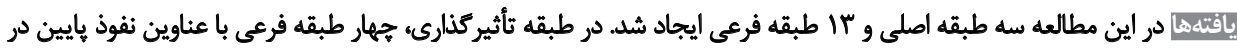

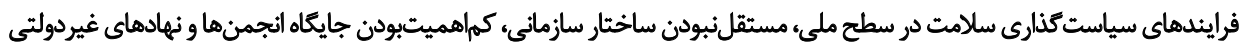

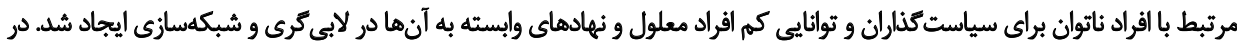

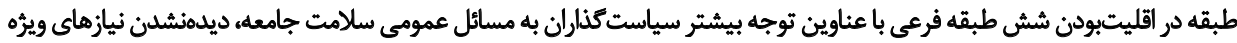

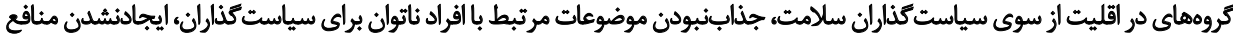

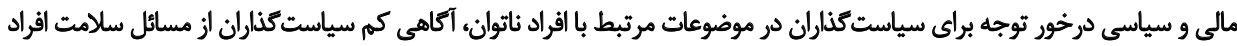

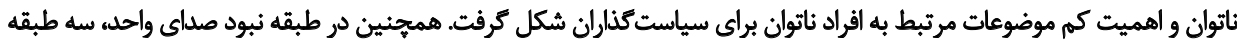

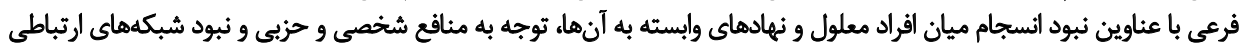

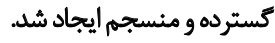

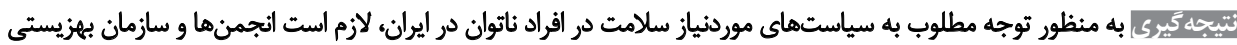

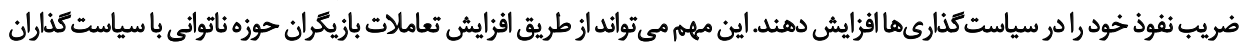

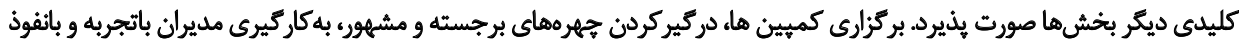

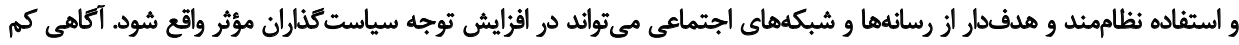

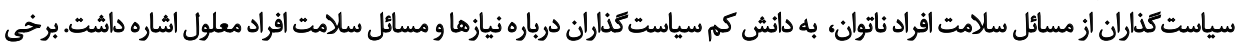

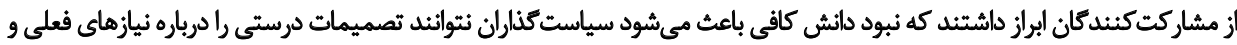
آينده افراد ناتوان بكيرند.

كليدوأرهها: سياستكذارى سلامت، افروان

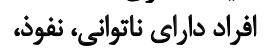
دستوركذارى، ايران

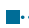

* نويسنده مسئول:

دكتر امير حسين تكيان

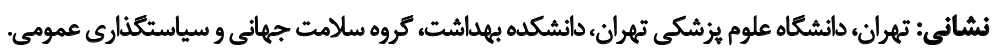
تلفي:

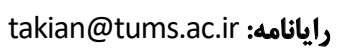




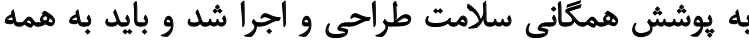

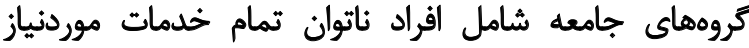

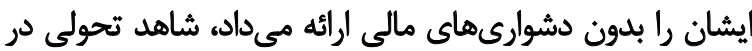

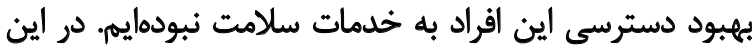

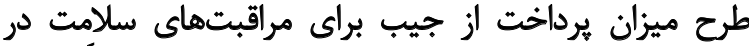

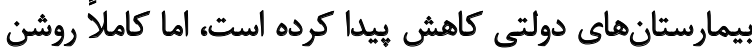

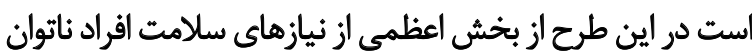

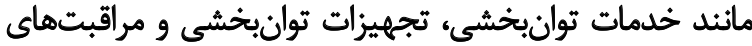

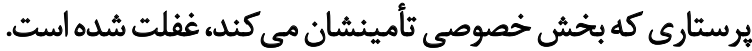

همجنين بايد اشاره كرد بسيارى از نيازهاى سلامت افراد

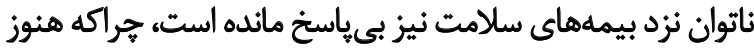

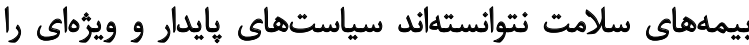

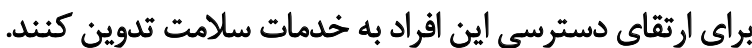

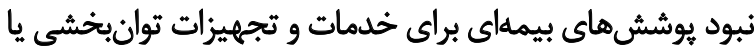

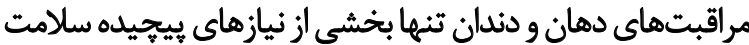

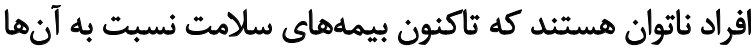

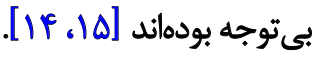

در مطالعات مختلفى كه در ارتباط با شناسايى نيازهاي سلامت

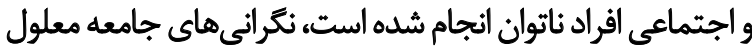

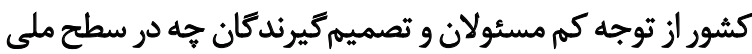

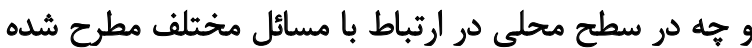

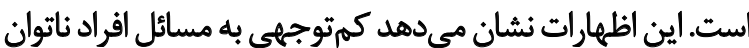

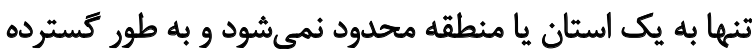

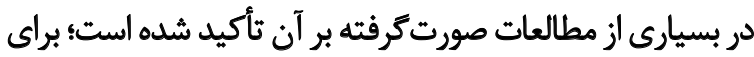

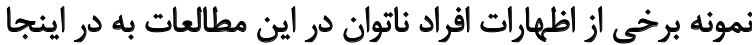

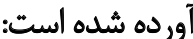

المتأسفانه اكثر مسئولان مسئله را مىشناسند اما به آن آن

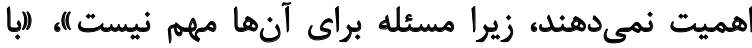

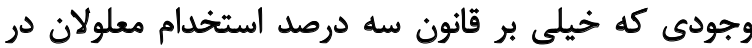

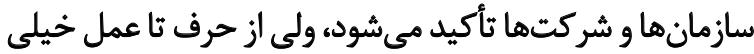

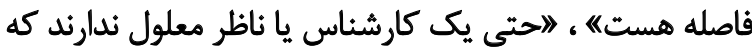

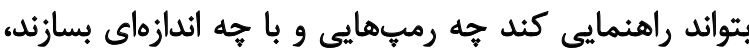

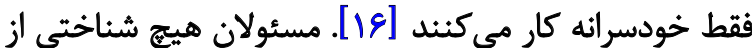

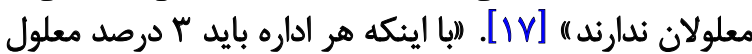

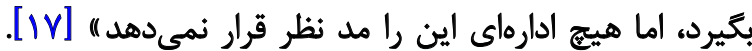

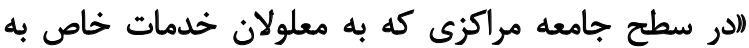

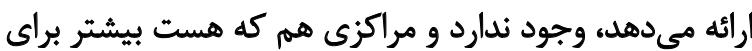

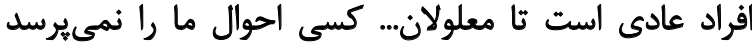

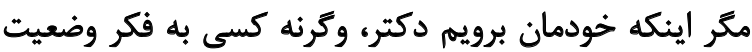

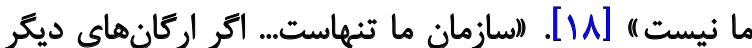

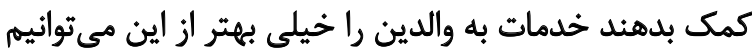

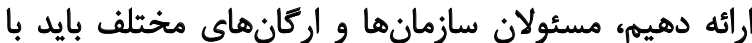

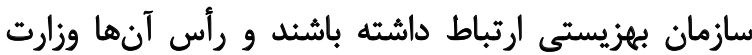

مقلمه

تحقيقات نشان مي دهند سطح سلامت افراد ناتوان در مقايسه

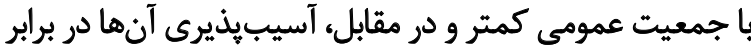

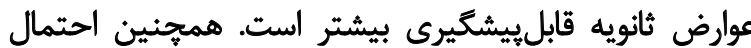

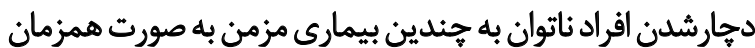

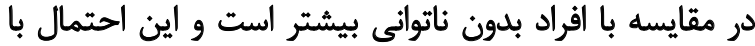

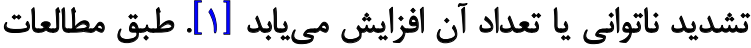

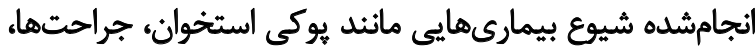

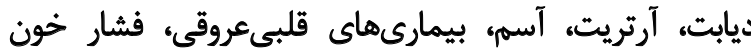

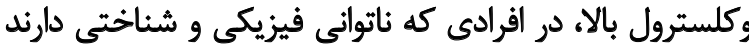
بيشتر از جمعيت عمومى است [r] بالان.

علاوه بر اين، نتايج برخى مطالعات حاكى از آن است كه

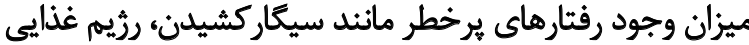

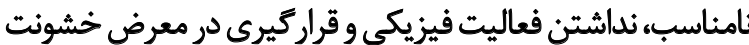

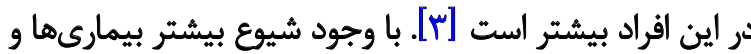

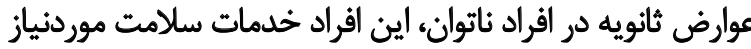

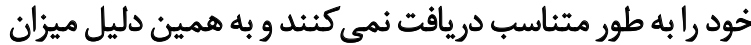

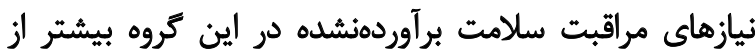

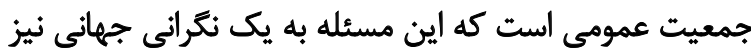

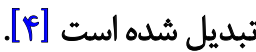

مطابق نتايج سرشمارىهاى ملى در سالهاى كذشتثه، افراد

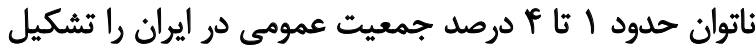

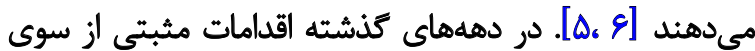

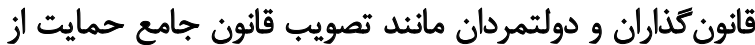

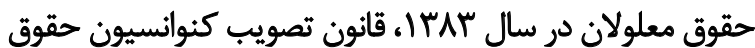

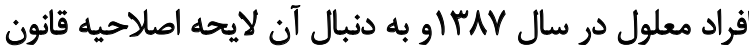

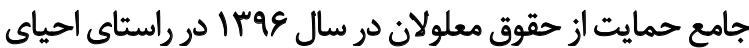

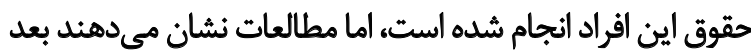

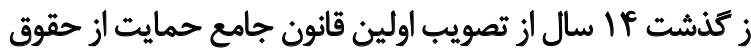

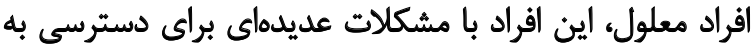
خلمات سالامت روبهرو هستيند.

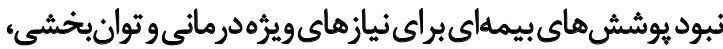

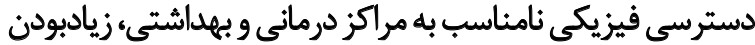

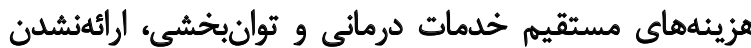

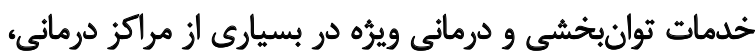

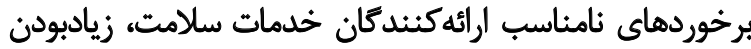
هزينه تجهيزات توانبخشى و نبود دسترسى نامناسب به به سيستم

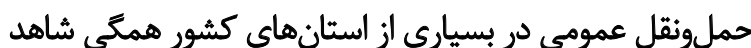

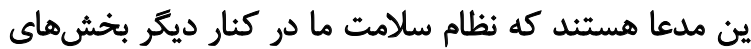

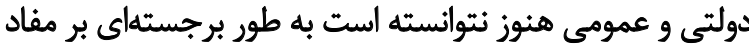
قوانين موجود جامه عمل بيوشاند [C-If] براى نمونه در طرح تحول سلامت كه با هدف دسترسى 
ورش بروسى

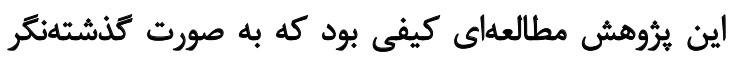

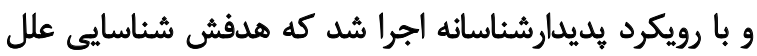

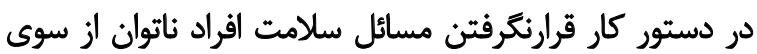

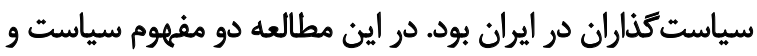

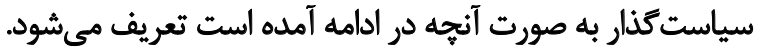

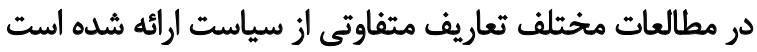

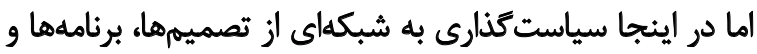

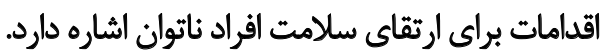
همجنين در اين مطالعه سياست كذار به افرادي اطلاق مى ريد كه در

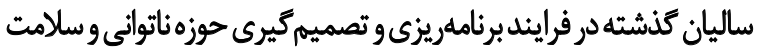

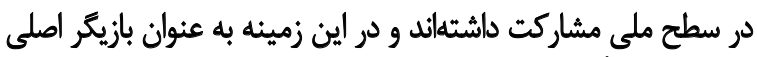

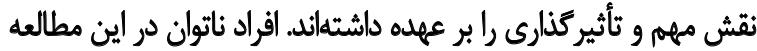

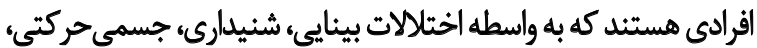

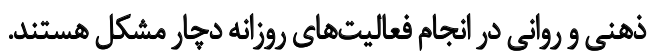

ببهداشت است كه مىتواند با مجموعههاى ذىربطش ارتباط با دستكاههاى ما را قوىتر كنده " [19].

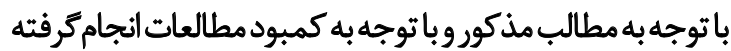

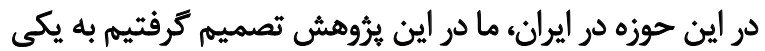

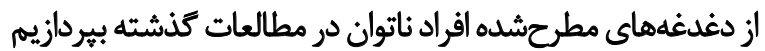

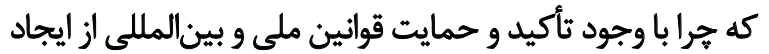

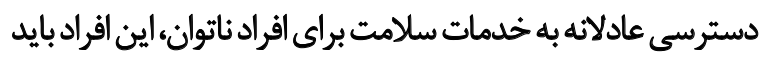

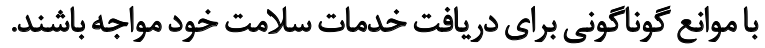

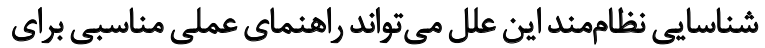

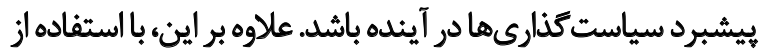

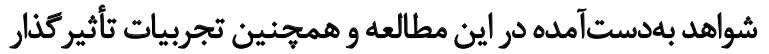

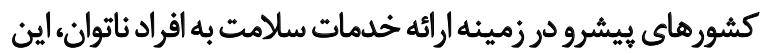

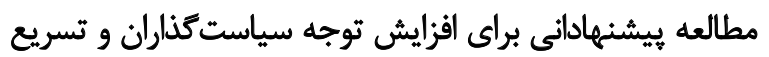
روند در دستور كار قرارگرفتن مسائل سلامت اين شهروندان ارئ ارئه

$\log _{5}$

جدول ا. مشخصات كلى افراد شركت كنيده در مطالعه

\begin{tabular}{|c|c|c|}
\hline 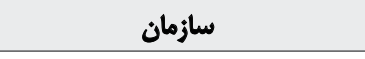 & حوزه فعاليث & شماره افراد شركت كثئده \\
\hline وزارت بهداشت، درمان و آموزش يزشكىى & بيمdهاى سلامت & 1 \\
\hline وزارت بهداشت، درمان و أموزش يزّشكى & توانيخشىى & r \\
\hline بياد شهيد و امور إيثاركران & توانبخُشى & $r$ \\
\hline وزارت بهداشت، درمان و آموزش يزٔشكى & برنامهريزى و اقتصاد سلامت & r \\
\hline انجمن باور & حقوق الفراد معلول & $\Delta$ \\
\hline سازمان بهزيستى كشور & توانبخشى & 8 \\
\hline سازمان بيمه سلامت ايرالن & ييمه سلامت & $\gamma$ \\
\hline انجمن جامعه معلولان ايران & ثاتوائى و معلوليت & $\wedge$ \\
\hline سازمان تامين اجتماعى & بيمه سلامت & 9 \\
\hline سازمان تأمين اجتماعى & بيمه سلامت & 1. \\
\hline سازمان بيزيستى كشور & توانبخشى & 11 \\
\hline شهردارى تهران & مناسبسازى ثشهرى & ir \\
\hline 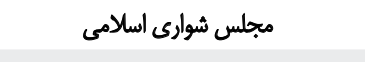 & ق قانون كذارى & ir \\
\hline وزارت تعاون، كار و رفاه اجتماعى & حقوق الفراد معلول & if \\
\hline وزارت بهداشث، درمان و أموزش يزشكى & 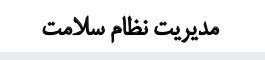 & 10 \\
\hline سازمان بهزيستى كشور & مناسبسازي شيهرى & 18 \\
\hline سازمان بهزيستى كشور & توانبخشى & iv \\
\hline سازمان بيزيستى كشور & توانبخشى & in \\
\hline سازمان بهزيستى كشور & توانيخشى & 19 \\
\hline سازمان ييمه سلامت إيران & بيمه سلامت & r. \\
\hline انجمن باور & حقوق الفراد معلول & r \\
\hline وزارت بهداشت، درمان و آموزش يزيكىى & ازثنيكى & $\pi$ \\
\hline
\end{tabular}


كدها مقايسه شد و كدهايى كه به مفاهيم مشترك اشاره داشتند

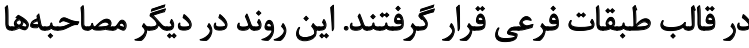

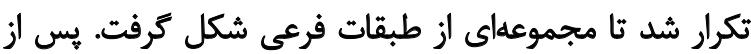

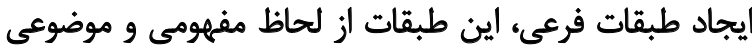

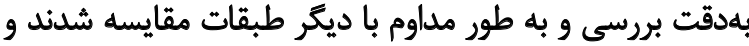

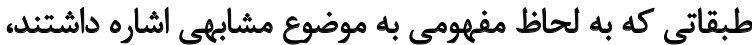

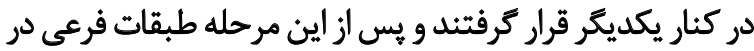

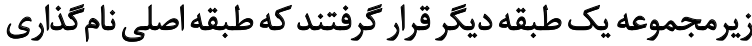

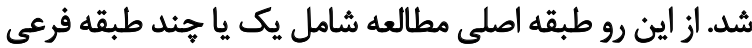

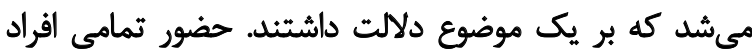

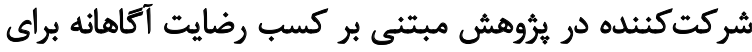

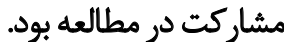

يافتلها

در اين مطالعه با توجه به هدف مطالعه سه طبقه اصلى با باليقا

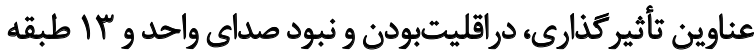

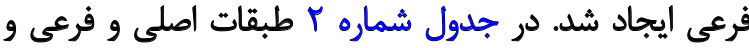

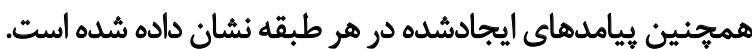

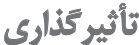

برخى از مصاحبه شوندكان بيان مى كردند كه سازمان بهزيستى به دليل آنكه زيرمجموعه يك وزيك وزارتخانه است، جايكاه سياسي

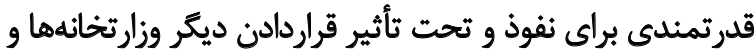

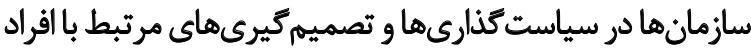

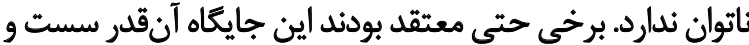

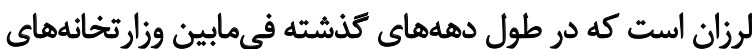
مختلف جابهجا مى شده است.

برخى از سياست كذاران سازمان بهزيستى بيان كردند كه

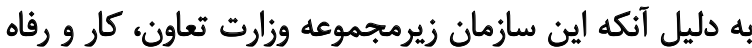

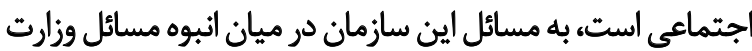

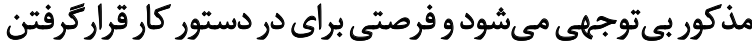

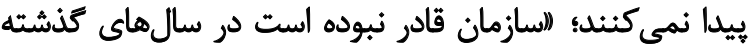

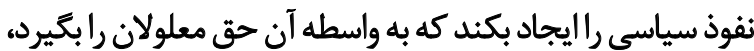

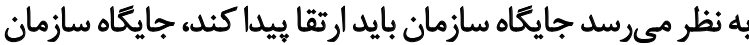

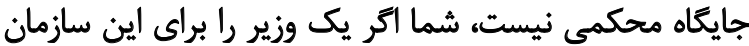

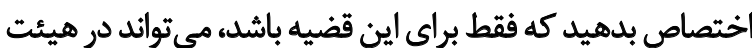

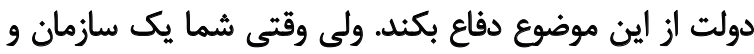

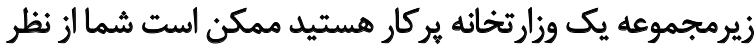

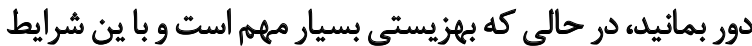

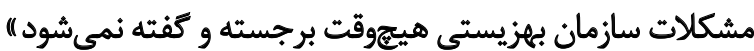

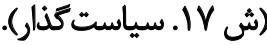

همجنين برخى از مصاحبهشوندكان بيان كردند كه افراد

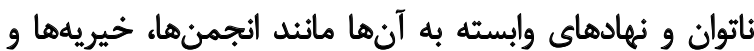

جامعه مطالعهشده شامل همه افراد ذيىنفع و صاحبنظرى

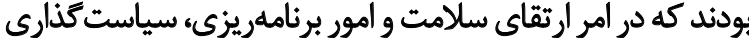

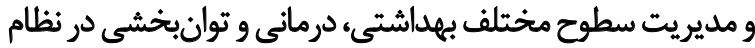

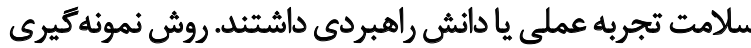

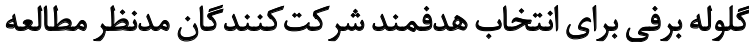

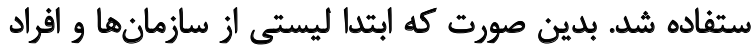

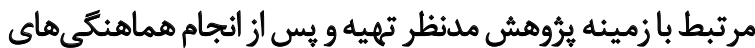

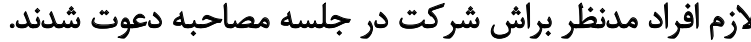

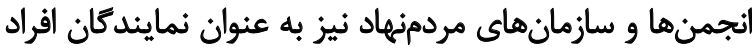

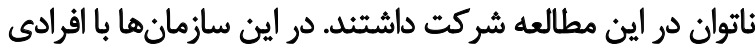

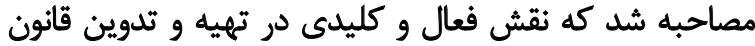

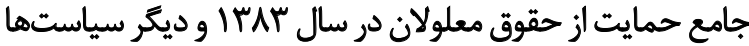
و قوائين بعد از آن داشتند.

براى هدايت جلسه مصاحبه و جمع آورى هدفمند دادههاى

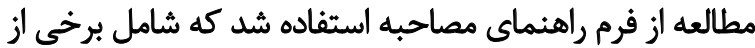

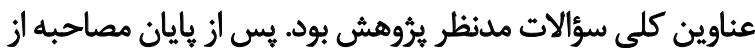

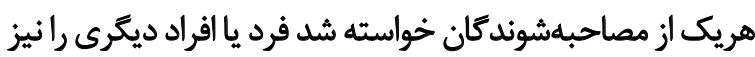

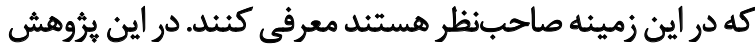

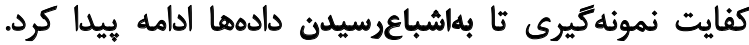

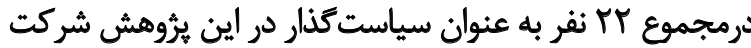

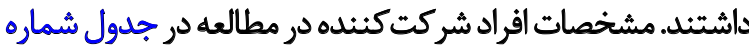

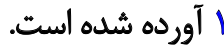

جمعآورى اطلاعات از طريق مصاحبه مائ انفرادى

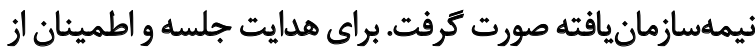

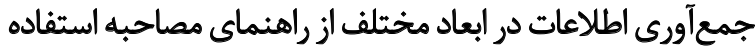

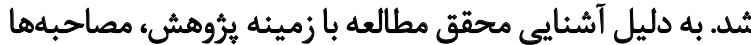

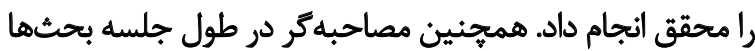

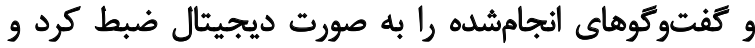

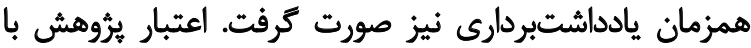

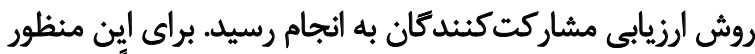

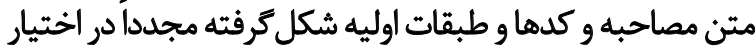

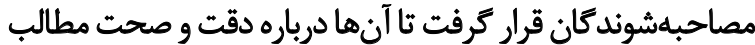

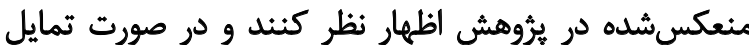

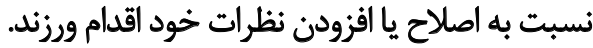

تحليل دادههاى كيفى

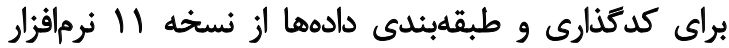

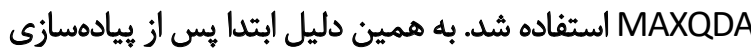

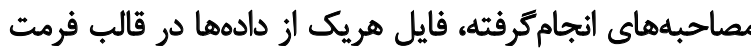

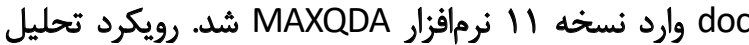

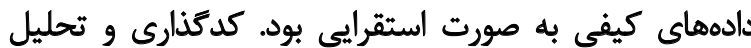

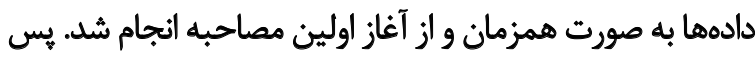

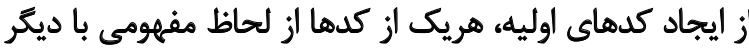


جدول ب. موانع در دستور كار قرارنكرفتن مسائل سلامت افراد ناتوان از منظر سياست كذاران

\begin{tabular}{|c|c|c|}
\hline يبامدها & طبقه فرعى & طبقه اصلى \\
\hline 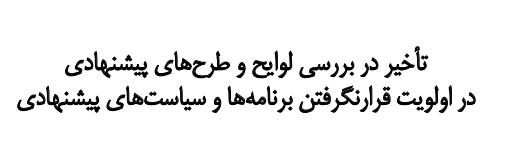 & 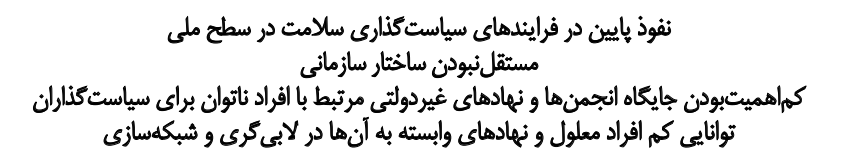 & تأثيركنارى \\
\hline 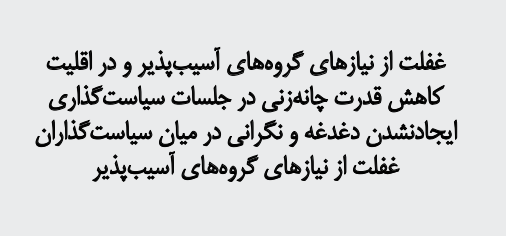 & 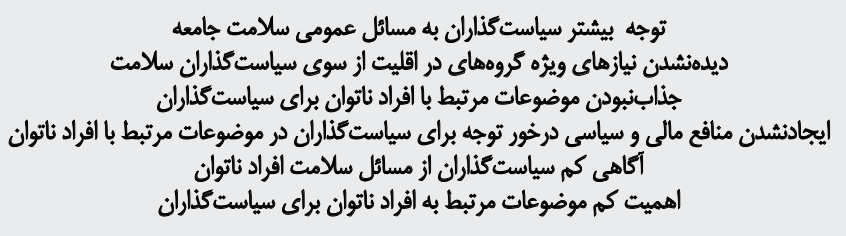 & در اقليت \\
\hline 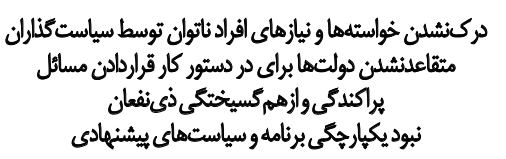 & 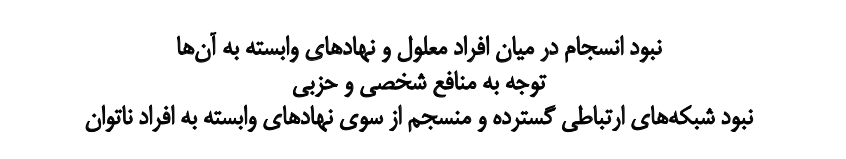 & نيود صداى والحد \\
\hline
\end{tabular}

توانبخننى

است، ما مجبوريم اجرا بكنيم و نميثوانيم بكويم بار مالي دارد و

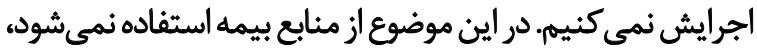

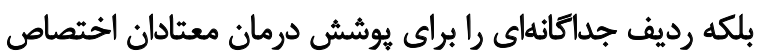

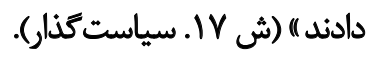

$$
\text { نو }
$$

برخى از مصاحبهشوندكان بيان كردند كه منافع و نيازهاى

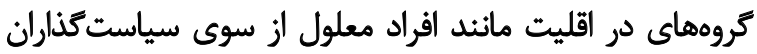

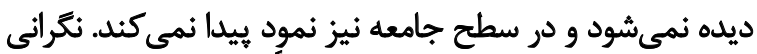

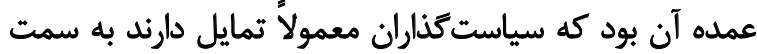

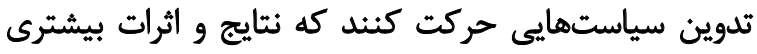

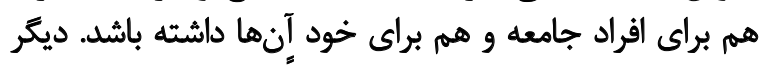

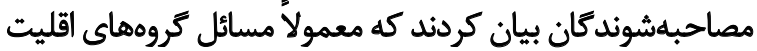

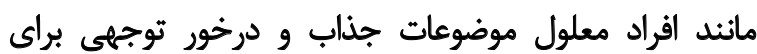
سياست كذاران نيستند.

سياست كذاران تمايل دارند انرزي كارى خود را در نهادها و يستهايي صرف كنئ كله در متن توجه سياست كمناران كليدى

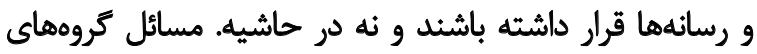

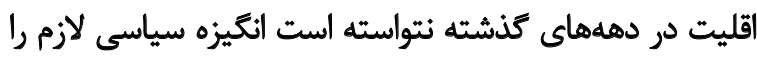

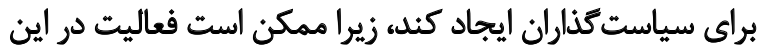

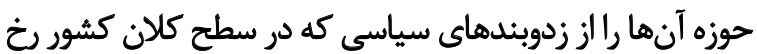

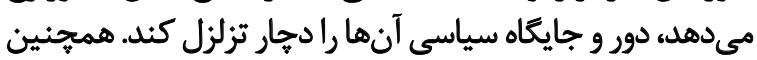

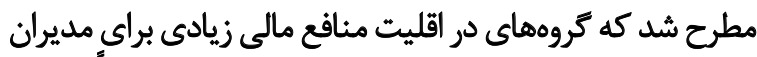

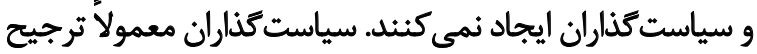

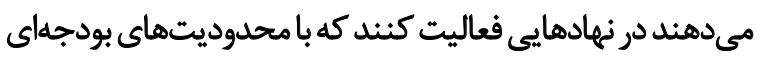

سازمان بهزيستى نتواستهاند در ساليان كذشته لابي هاي سياسى

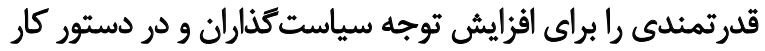

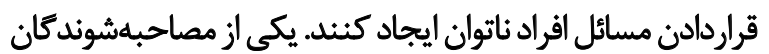

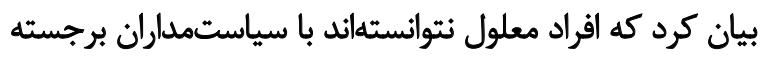

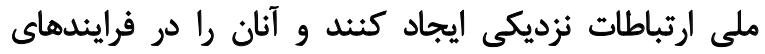

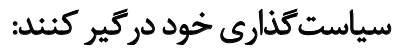

الادر كشورها توسعهيافته به نظرم آنجه مؤثر بوده ولى ما در

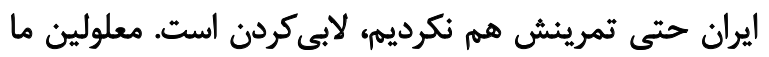

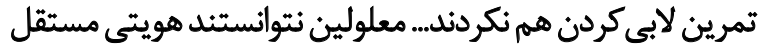

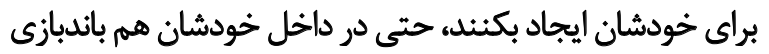

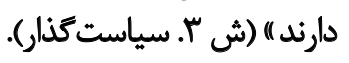

يكى از سياست كذاران در حوزه بيمه سلامت به اين اشاره

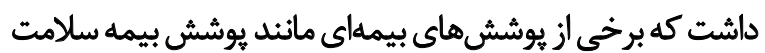

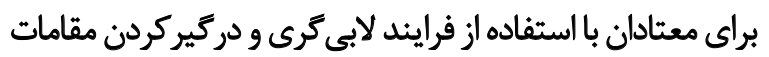

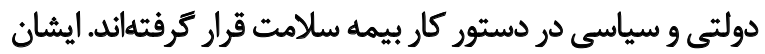

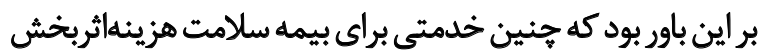

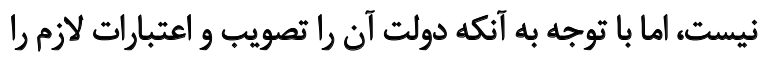
براى آن ثأمين كرده، بيمه سلامت ملزم به اجراى آن آن شده است: الابعضى جيزها با لابي اثفاق مي افتند. يك بار مجمع تشخيص

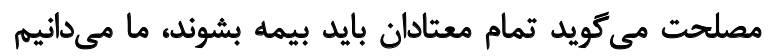

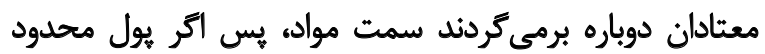

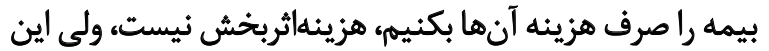

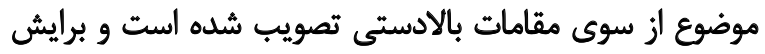

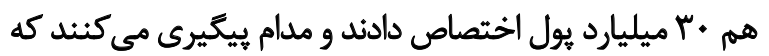

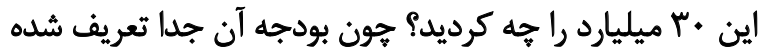


نبود دغلغغه نسبت به مسائل سلامت اقراد ناتوان در وزارت

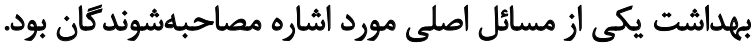

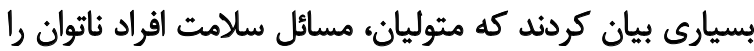

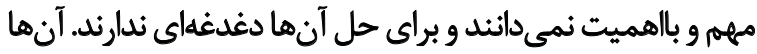

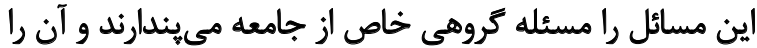

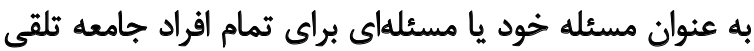

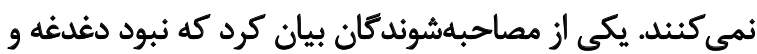

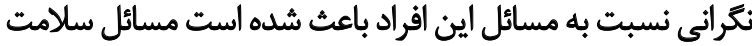

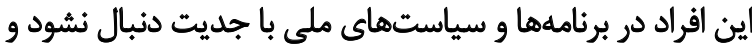

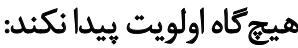

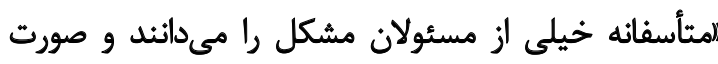

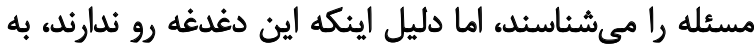

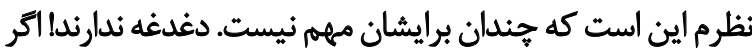

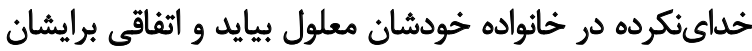

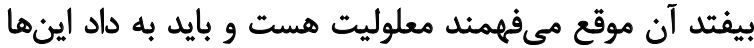
رسيد. بايد كمكشان كرد.) (ش هـ هـ سياست مثذار)

نبود صداي واحد

برخى از مصاحبهشوندكان از تفرقه و نبود اتحاد بين افراد

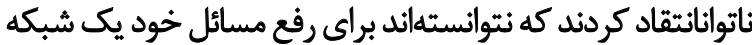

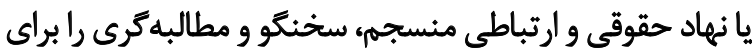

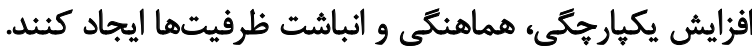

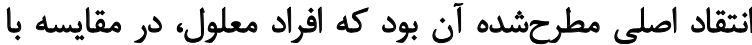

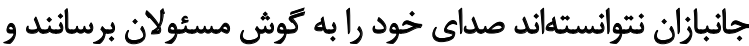

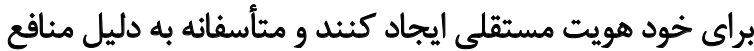

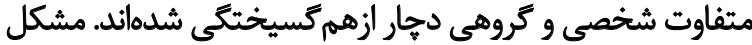

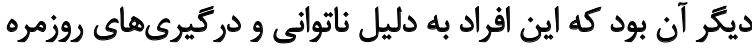

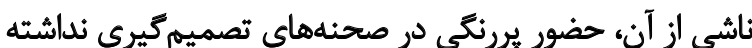

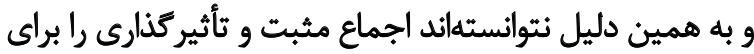
مطالبات و خواستههاى خود ايجاد كنئد. الخود معلولان بايد مقدارى مشاركت خودشان رو بيشتر كنند.

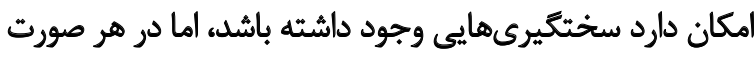

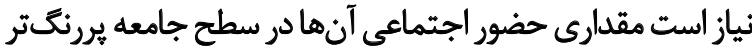

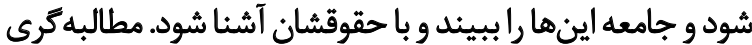

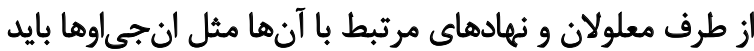

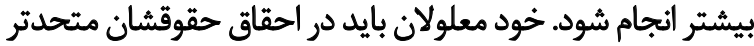

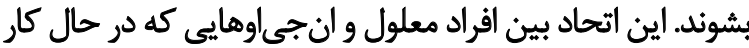

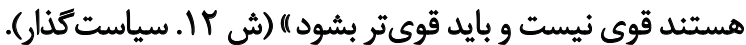

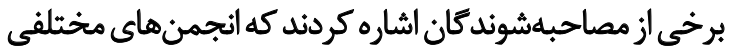

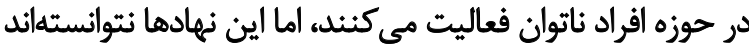

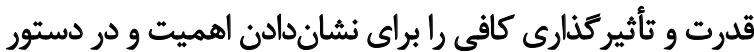
كار قراردادن مسائل ونيازهاي افراد معادي ائلول ايجاد كنيند كه متأسفانه
كمترى روبهرو باشد و از سوى ديكَر منافع مالى شُخصى حُود را

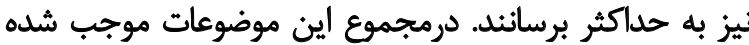

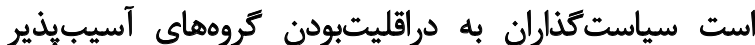

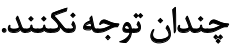

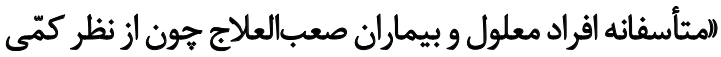

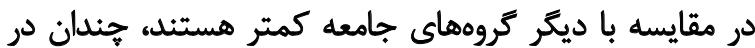

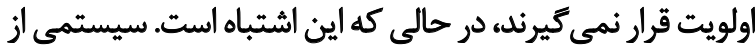

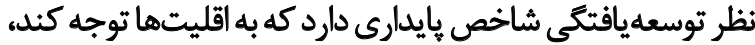

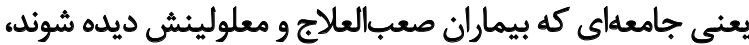

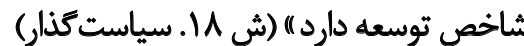

برخى از مصاحبهشوندكان بيان كردند كه آكاهى و دانش نسبت به مفاهيم ناتوانى و معلوليت در ميان سياست كذار باران ريان رشد

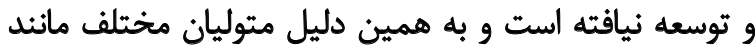

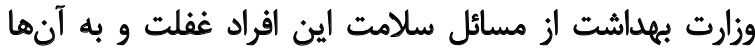

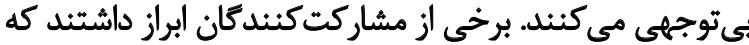

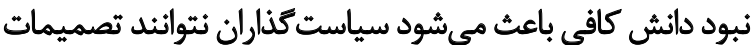

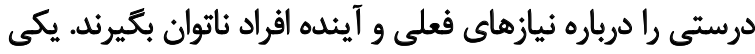

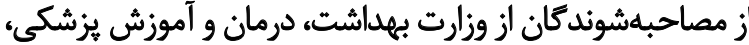

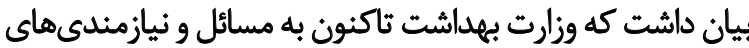

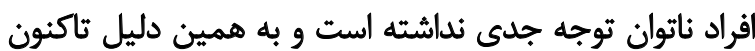

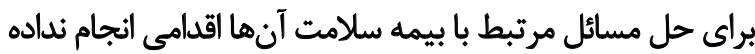
إيتي:

البه نظرم بيشتر مشكلات به خلأ بلوغ فكرى آن كروهي

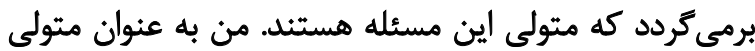

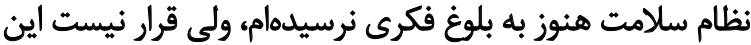

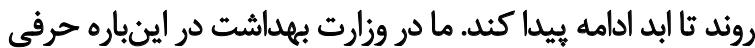

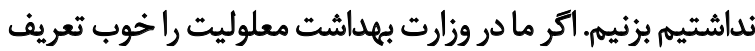

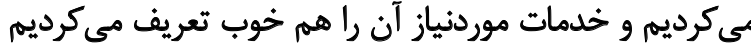

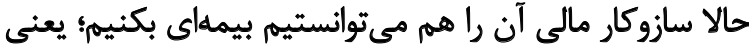

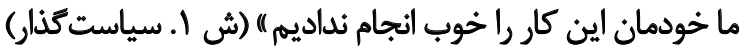
نبود بلوغ فكرى فقط محدود به يك نهاد و سازمان نيست، بلكه

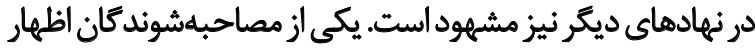

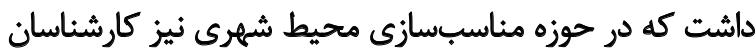

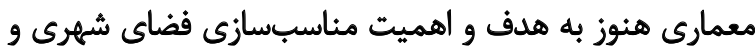

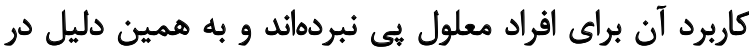
ساختوسازهاى خود نيز مقررات و استانداردهاى منائ مناسبسازي

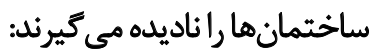

(اما جلسهاى كذاشتيه درباره مناسبسازى محيط شهرى و همه

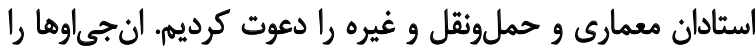

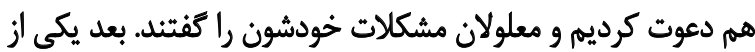

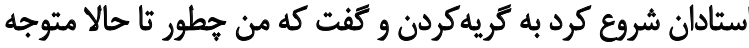

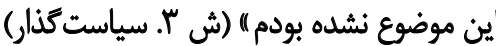


قدرت و نفوذ كافى را براي در دستور كار قراردادن مسائل سلامت

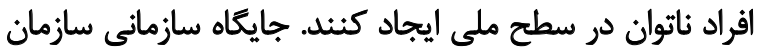

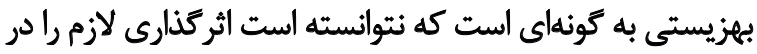

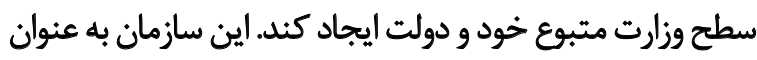

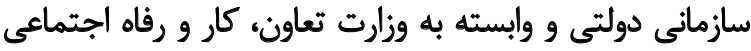

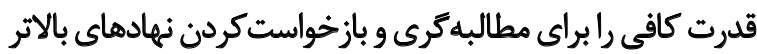

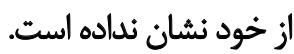

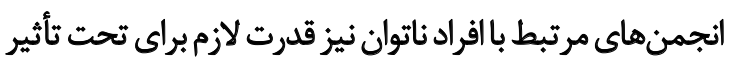

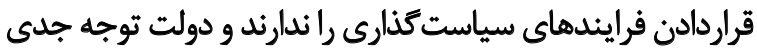

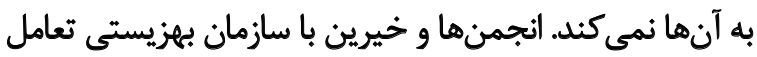

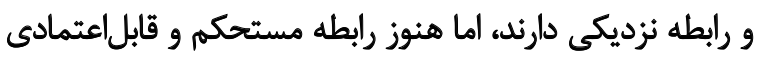

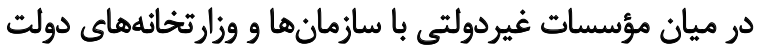

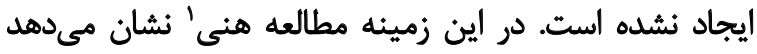

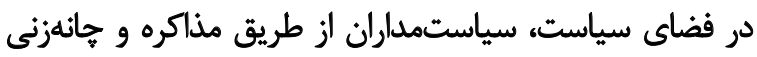

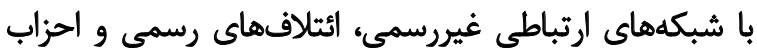

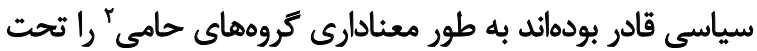

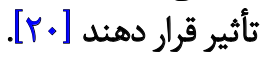

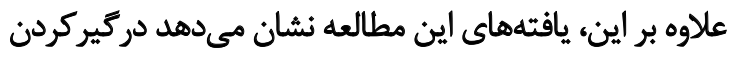

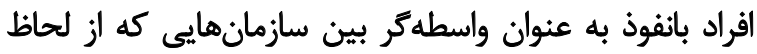

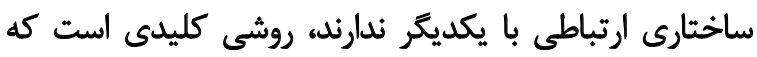

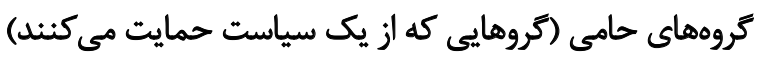

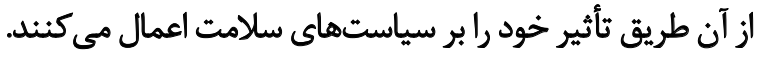

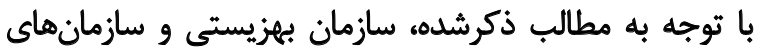

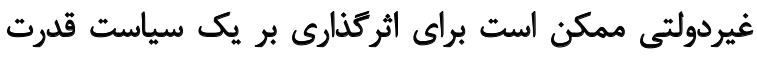

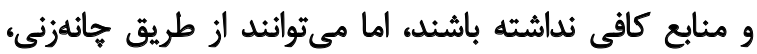

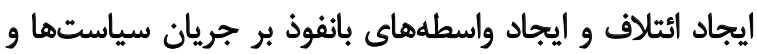

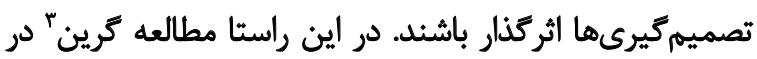

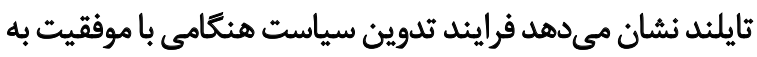

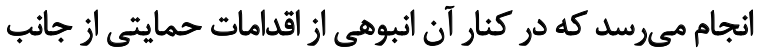

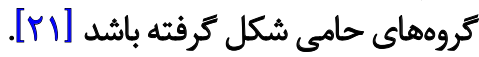

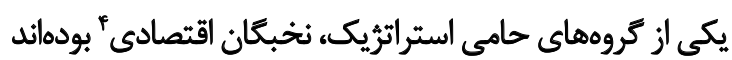

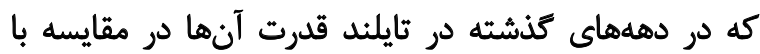

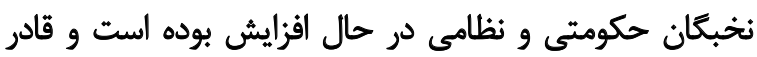

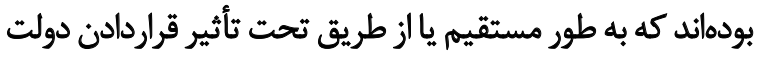

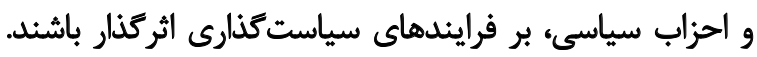

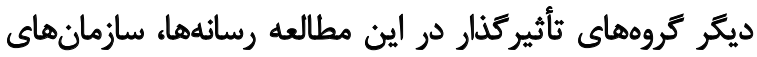

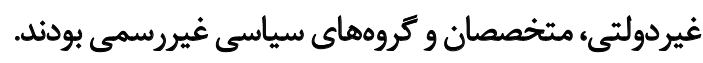
به اعتقاد شركت كئندكان در اين مطالعه، افراد ناتوان و نهادهاي

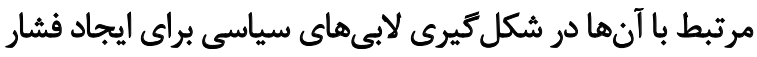

1. Heaney

2. Interest groups

3. Green

4. Economic elite
از ديد دولت نيز كماهميت ينداشته شدهاثد. مصاحبهشوندكان

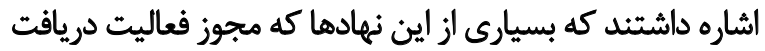

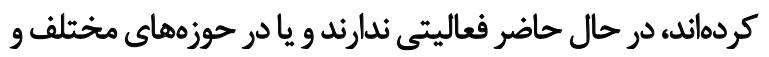

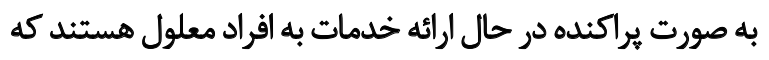

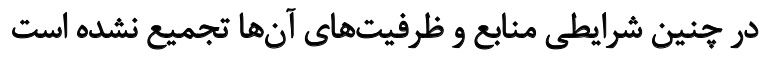
و صداى واحد و يكسانى براى احقاق حقوق خود ايجاد نمى كنيند.

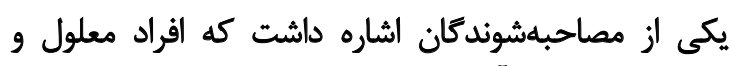

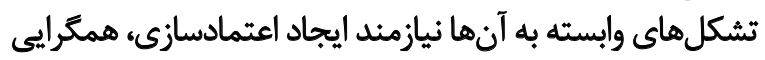

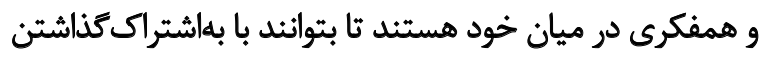

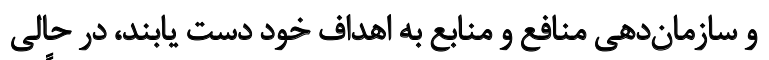

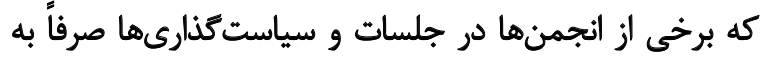

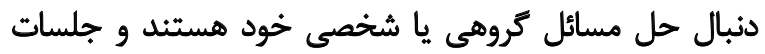

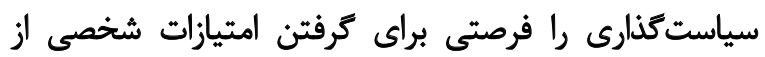
سياست كذاران مي ريندارند:

\section{الجامعه معلولان اكر به همفكرى و همكرايى برسند بهتر از}

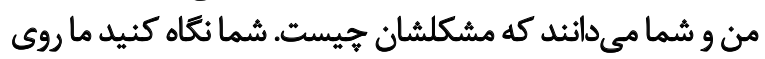

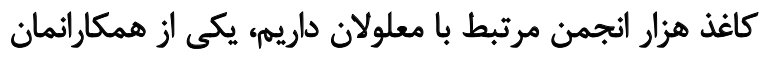

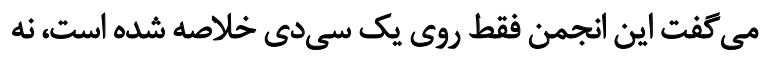

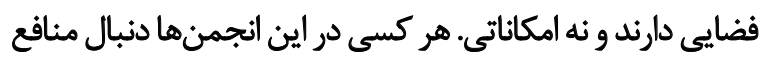

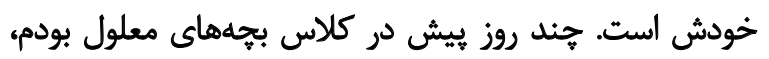

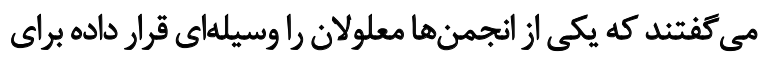

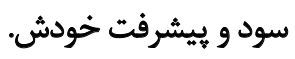

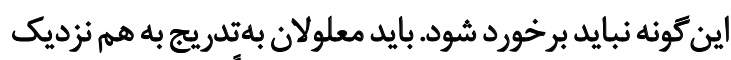

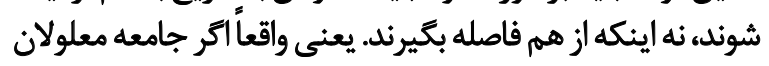

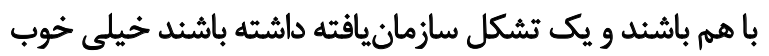

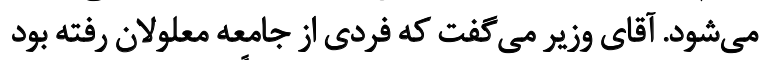

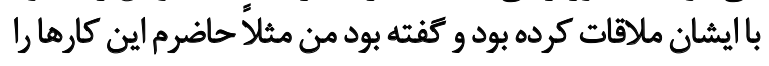

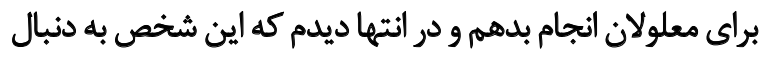
منافعى براى خودش است نه معلولان. (ش ؤ سياست كذار ).

بحث

اين مطالعه با هدف شناسايى علل در دستور كار قرارنترفتن

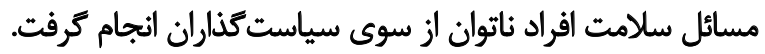

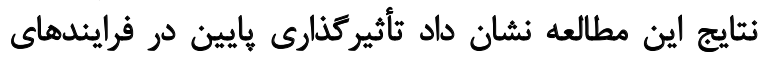

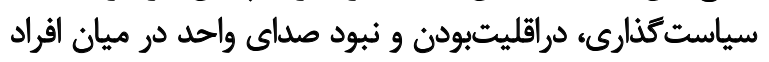

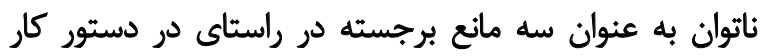

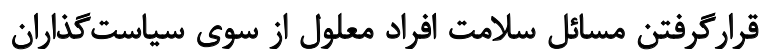

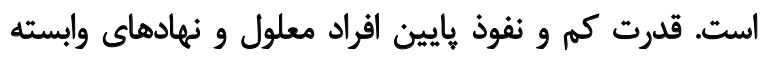

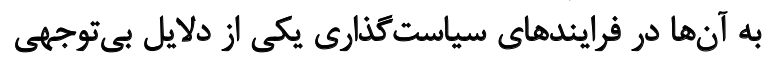
سياست كذاران به موضوعات ناتوانى در سطح ملى بلى بود.

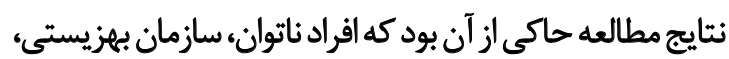

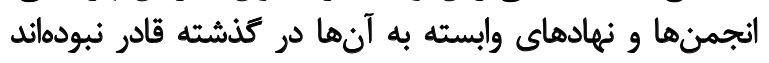


دركيرنكردن اشخاص بانفوذ سياسى و ايجاد انجمن ملى ناتوانى

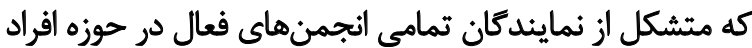

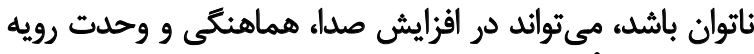

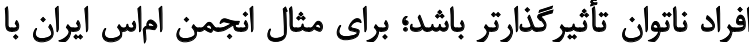

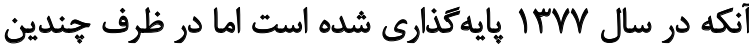

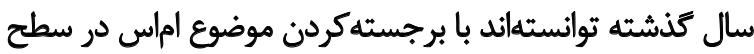

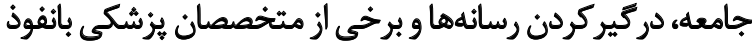

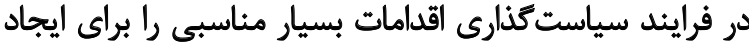

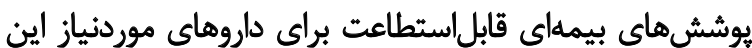
اقراد دركير اين بيماري انجام دهند.

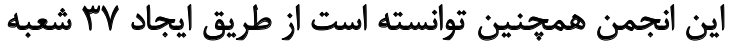

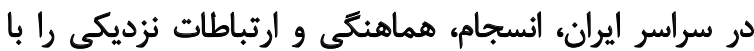

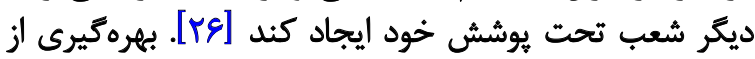

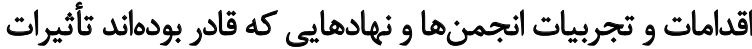

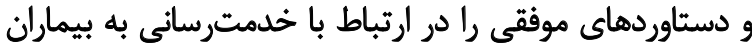

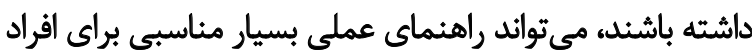
معلول و ذيىنفعان دركير در اين قضيه باشئ راشدي

\section{يئشنهاداثت سياستئي}

\section{بركزارى كميينها از سوى افراد ناتوان و نهادهاى وابسته

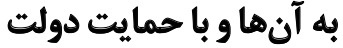

روند تحولات اجتماعى و سياسى ناتوانى در كشورهاى

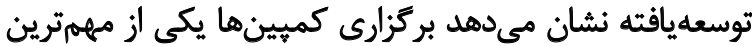

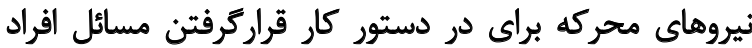

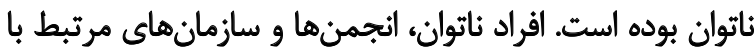

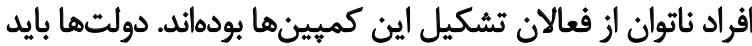

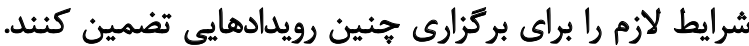

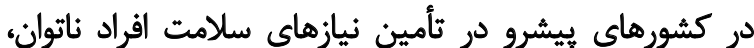

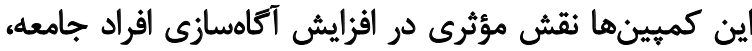

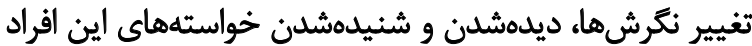

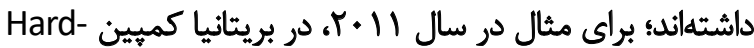

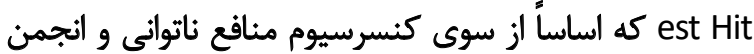

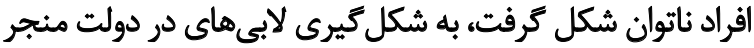

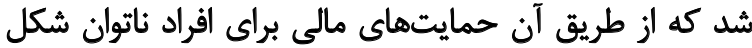

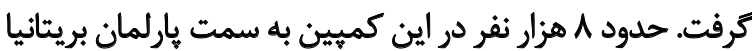

راهييمايى كردند [rV]

دركيركردن جهر ههاى برجسته و بانفوذ جامعه در فرايند

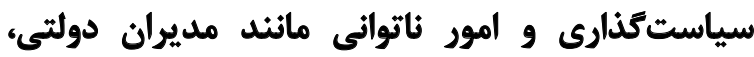
روحائيون، هئرمندان و ورزشكاران

روند تحولات كشورهاى بيشرو در زمينه ناتوانى نشان مى دهد

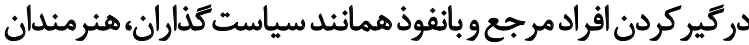

و تأثيركذارى بر تصميمات دولت ناموفق بودهاند. بر اساس نياس

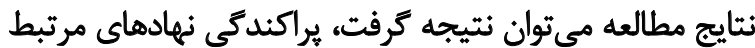

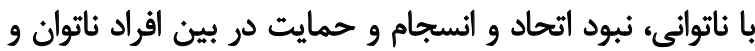

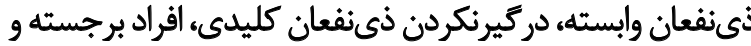

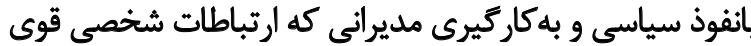

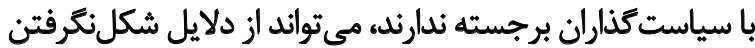

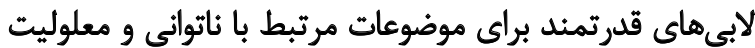

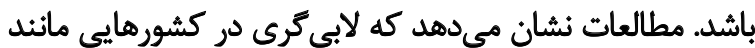

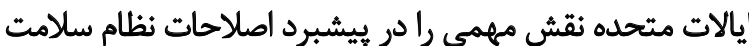

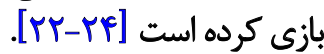

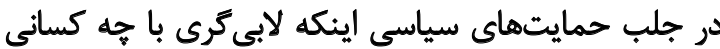

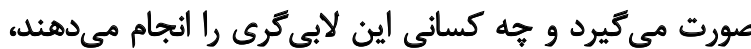

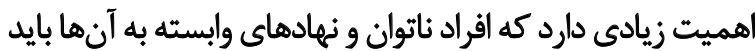

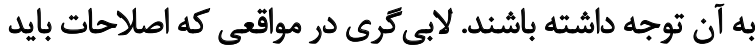

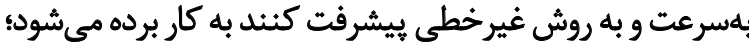

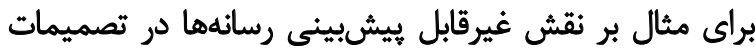

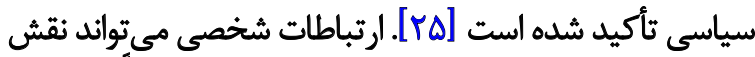

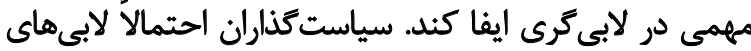

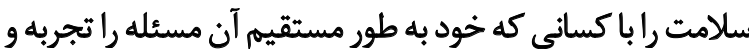

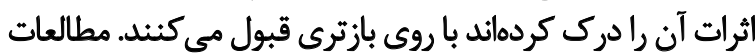

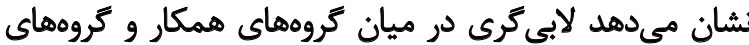

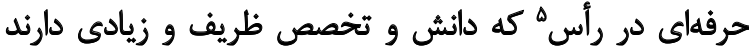

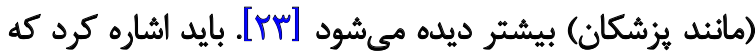

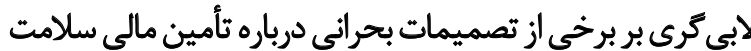

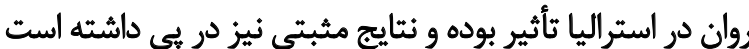

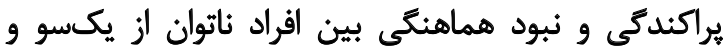

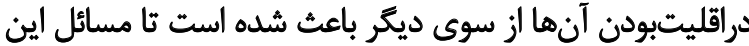

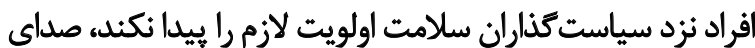

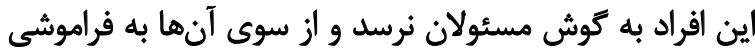

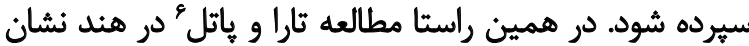

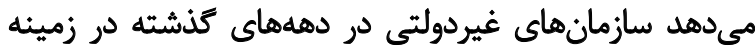

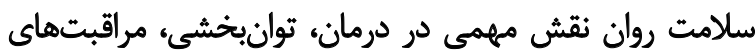

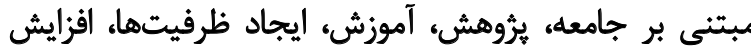
آكاهي و لايتى كرى بازى كردهائد.

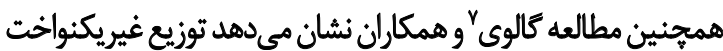

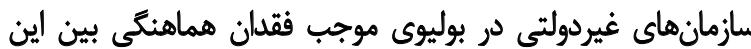

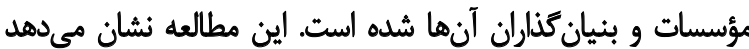

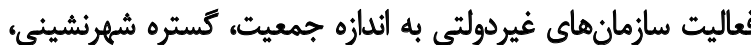

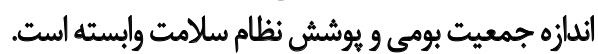


نفر را از مسائل موجود آكاه كند. علاوه بر اين، انتشار برنامههاى

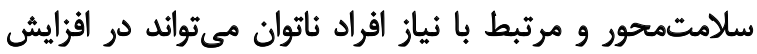

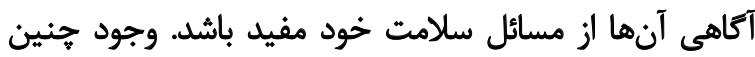

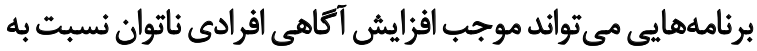

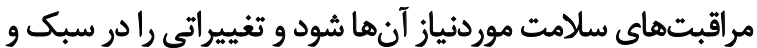
كيفيت زندكى آنها به وجود آوردا

بركزارى همايشها، نشستها و كفتمانهاى سياستى

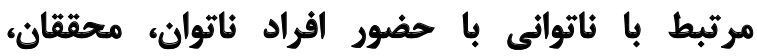

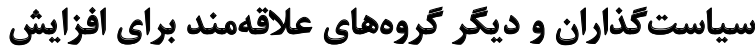
آكاهي، شناسايي مسائل، اولويتها و ورائ راهكارها

برَّزارى همايشها و نشستها فرصت بسيار مناسبى براى إئ

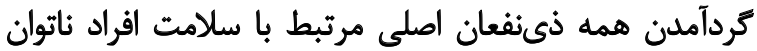

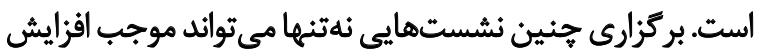

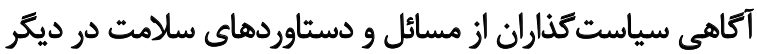

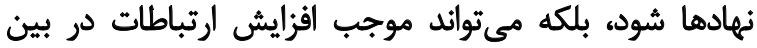

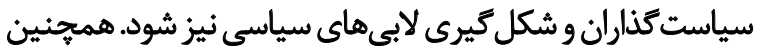

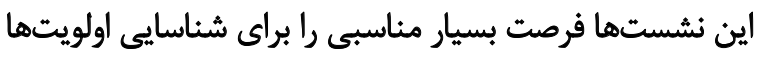

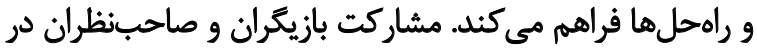

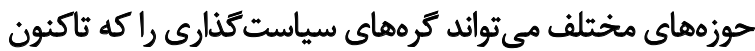

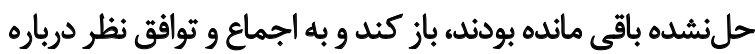
اين مشكلات منجر شود.

ايجاد يك انجمن يا سازمان ملى غيردولتى براي تقويت

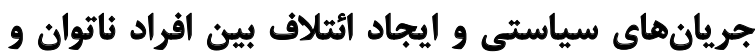
نهادهاي وابسته به آنها وان ايجا

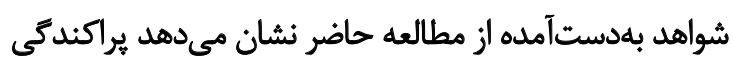

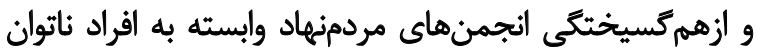

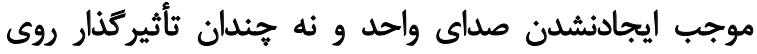

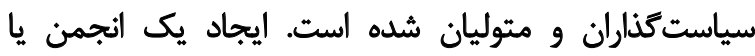

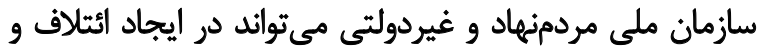

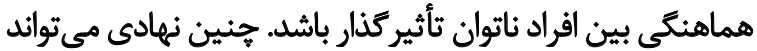

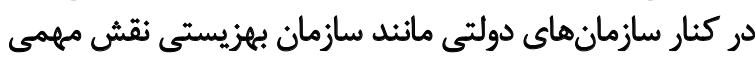

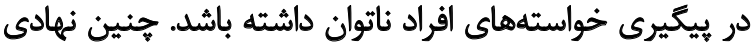

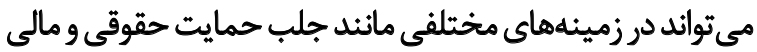
واجتماعى، براى افراد ناتوان تأثير كذار باشد.

راماندازى جنين نهادى از سوى برخى سياست كذاران

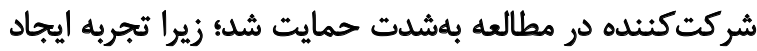

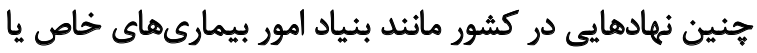

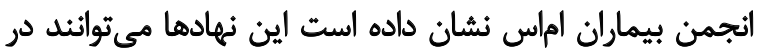

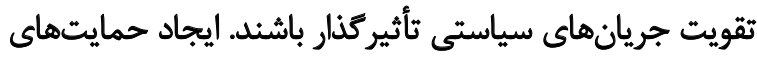

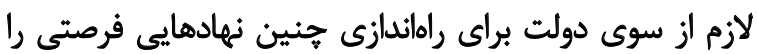

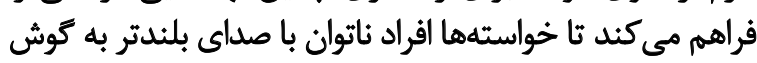

و ورزشكاران كه خود ناتوان بودهاند يا اينكه سابقه فعاليت در اين

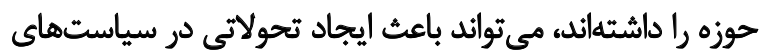
مرتبط با ناتوانى شود.

بهكارتماشتن اين افراد در بستهاي مديريتى يا به عنوان

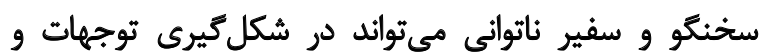

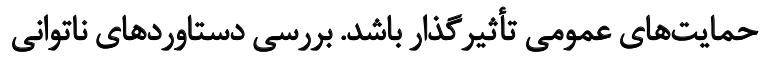

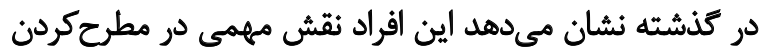

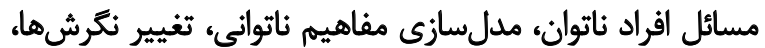

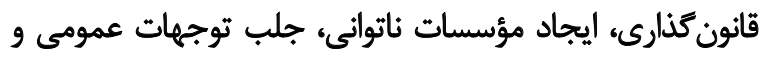

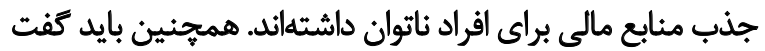

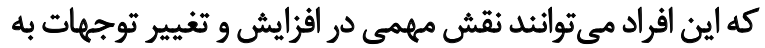
سمت افراد ناتوان داشته باشند.

دركيرشدن اين افراد در امور مختلف مرتبط با افراد ناد ناتوان

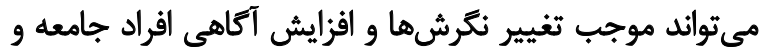

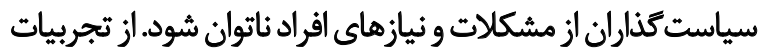

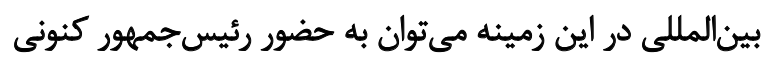

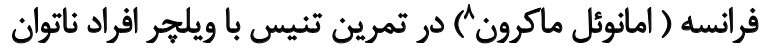

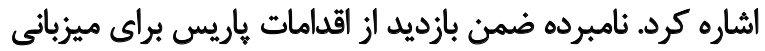

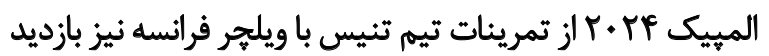

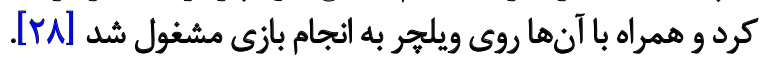

\section{بهكاركيرى مديران باتجربه و بانفوذ در حوزه ناتوانى}

بهكاركيرى مديران باتجربه و بانفوذ در حوزه سياست دذارى

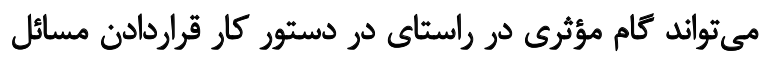

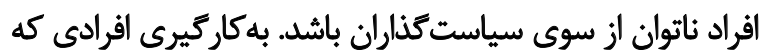

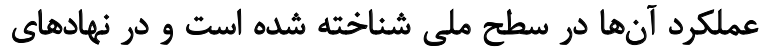

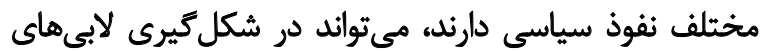

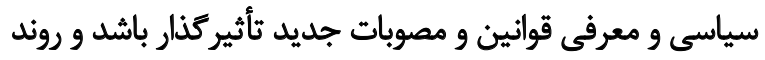

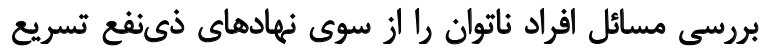

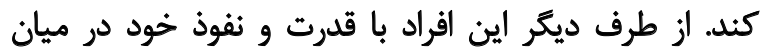

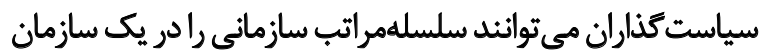

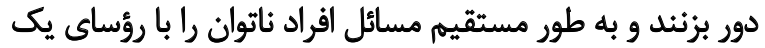

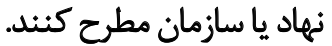

دركيركردن رسانههاي جمعى در انتشار اطلاعات مرتبط

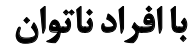

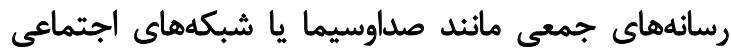
مى توانيد موجب ارتقاى فرهنگ ناتواني در كشور شوند. افزايش

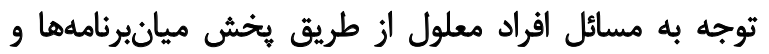

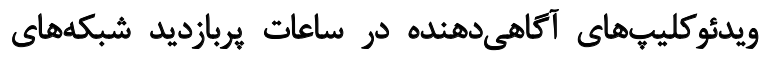
تلويزيونى يا راديويى مي تواند در كمترين زمان ممكن، ميليونها

8. Emmanuel Macron 
بنا به اظهار نويسندكان، در اين مقاله هيجَّونه تعارض منافعى

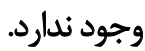

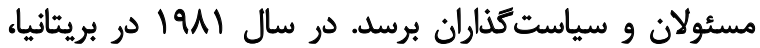

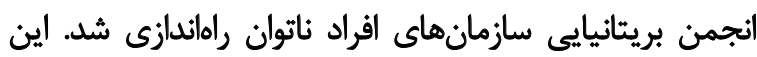

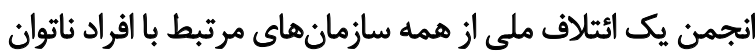

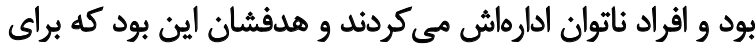

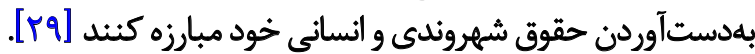

$$
\text { تيجنجئيرى }
$$

افراد ناتوان، انجمنهاو سازمان بهزيستى نياز دارند ضريب نفوذ

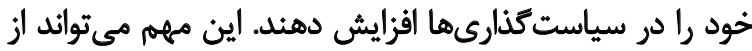

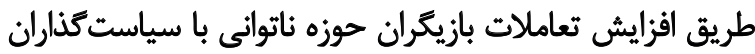

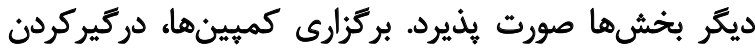

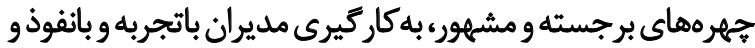

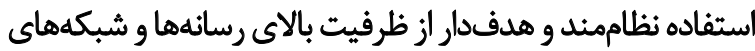

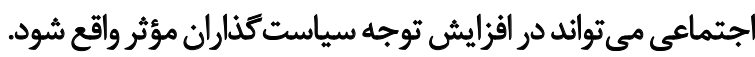

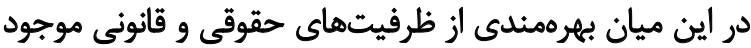

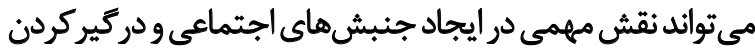

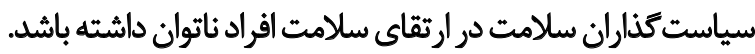
در خايان بيشنهاد ميشود در مطالعات آينده يروهشهائيى

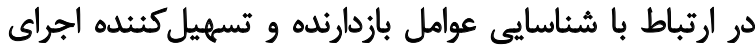

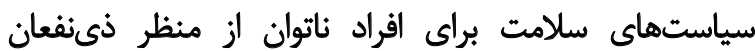

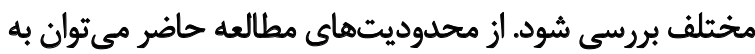

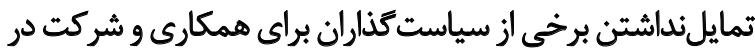

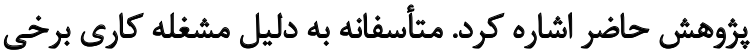

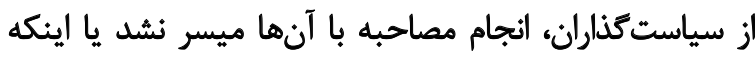
مصاحبهها در مدتزمان كوتاهترى به اتمام رسيد.

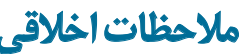

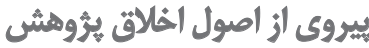

همه اصول اخلاقى در اين مقاله رعايت شده است.

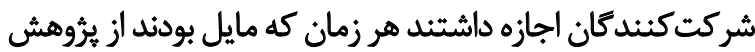

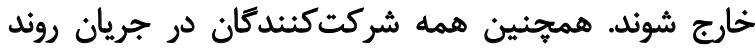
يثروهش بودئد.

$$
\text { حامي مالب }
$$

اين مقاله حامى مالى نداشته است.

$$
\text { مشاركت نويسند مَان }
$$

همه نويسندكان در طراحى، اجرا و نغارش همه بخشهاى ئروهش حاضر مشاركت داشتهاند.

$$
\text { تعارض منافع }
$$




\section{References}

[1] Naaldenberg J, Kuijken N, van Dooren K, de Valk HvSL. Topics, methods and challenges in health promotion for people with intellectual disabilities: A structured review of literature. Research in Developmental Disabilities. 2013; 34(12):4534-45. [DOI:10.1016/j.ridd.2013.09.029] [PMID]

[2] Mahmoudi E, Meade MA. Disparities in access to health care among adults with physical disabilities: Analysis of a representative national sample for a ten-year period. Disability and Health Journal. 2015; 8(2):182-90. [DOI:10.1016/j. dhjo.2014.08.007] [PMID]

[3] Hithersay R, Strydom A, Moulster G, Buszewicz M. Carer-led health interventions to monitor, promote and improve the health of adults with intellectual disabilities in the community: A systematic review. Research in Developmental Disabilities. 2014; 35(4):887-907. [DOI:10.1016/j.ridd.2014.01.010] [PMID]

[4] Havercamp SM, Scott HM. National health surveillance of adults with disabilities, adults with intellectual and developmental disabilities, and adults with no disabilities. Disability and Health Journal. 2015; 8(2):165-72. [DOI:10.1016/j. dhjo.2014.11.002] [PMID]

[5] Soltani S, Khosravi B, Salehiniya H. Prevalence of disability in Iran. Iranian Journal of Public Health. 2015; 44(10):1436-7. [PMID] [PMCID]

[6] Soltani S, Khosravi B, Salehiniya H. Prevalence of intellectual disability in Iran: Toward a new conceptual framework in data collection. Journal of Research in Medical Sciences. 2015; 20(7):714-5. [DOI:10.4103/1735-1995.166234] [PMID] [PMCID]

[7] Foroughan M. Psychological factors affecting rehabilitation of neurologic patients. Archives of Rehabilitation. 2001; 1(3):4852. [DOI: 10.5435/JAAOS-D-14-00225] [PMID]

[8] Hatami-Zadeh N, Ja'fari P, Vameghi R, Kazemnezhad A. [Client satisfaction of public and private rehabilitation day centers in Kordestan Province (Persian)]. Archives of Rehabilitation. 2008; 9(3-4):69-74.

[9] Zarei Matin H, Jandaghi G, Heydari F, Imani M. [The attitude of war handicaped toward the services recieved in terms of their needs (Persian)]. Iranian Journal of War and Public Health. 2010; 2(2):22-31.

[10] Khaksari A, Talebi MA, Goorkani R. [Pathology of public and private transportation of disabled people: A case study of Birjand City (Persian)]. Paper presented at: $12^{\text {th }}$ Iran's Transportation and Traffic Conference. 19-20 February 2013; Birjand, Iran.

[11] Raeis-Dana M, Tabatabaei-Nia M, Kamali M, Shafaroudi N. From diagnosis to coping: A journey with parents in the course of the disability of their children. Archives of Rehabilitation. 2009; 10(1):42-51.

[12] Seyed Hoseini Davarani H, Mousavi B, Karbalaeiesmaeili S, Soroush MR, Masoumi M. [Service satisfaction among war related bilateral lower limb amputation (Persian)]. Iranian Journal of War and Public Health. 2010; 3(1):49-54.
[13] Shakoori A, Shahmoradi F. [The study of accessibility of urban spaces and facilities in lived experience of visually impaired people in City of Tehran (Persian)]. 2015; 15(58):193-218.

[14] Soltani S, Takian A, Akbari Sari A, Majdzadeh R, Kamali M. Cultural barriers in access to healthcare services for people with disability in Iran: A qualitative study. Medical Journal of the Islamic Republic of Iran. 2017; 31(1):293-9. [DOI:10.14196/ mjiri.31.51] [PMID] [PMCID]

[15] Abdi K, Arab M, Khankeh HR, Kamali M, Rashidian A, Farahani FK, et al. Challenges in providing rehabilitation services for people with disabilities in Iran: A qualitative study. British Journal of Medicine \& Medical Research. 2016; 13(4):1-11. [DOI:10.19082/1476] [PMID] [PMCID]

[16] Farhoudian A, Soleimaninia L, Gharib M, Farhadi MH, Sadeghi $M$. [Survey of special needs in physically disabled people: $A$ qualitative study (Persian)]. Pajouhan Scientific Journal. 2013; 11(3):9-15.

[17] Nikkhah H, Fadaei S. [The study of economic, sociocultural and psychological needs of the disabled people (Persian)]. Journal of Hormozgan Cultural Research Review. 2016; 5(10):29-45

[18] Pashaei Sabet F, Norouzi Tabrizi K, Khankeh H, Fallahi Khoshkenab M. [Rehabilitation needs of patients with physical disabilities due to traffic accidents for returning to the community: A qualitative study (Persian)]. Iranian Journal of Rehabilitation Research in Nursing. 2014; 1(1):74-87.

[19] Alaee N, Mohammadi Shahboulaghi F, Khankeh H, Mohammad Khan Kermanshahi S. [Barriers to support for parents of children with cerebral palsy: A qualitative study (Persian)] Journal of Qualitative Research in Health Sciences. 2015; $3(4): 305-16$

[20] Smith DL. Disparities in health care access for women with disabilities in the United States from the 2006 National Health Interview Survey. Disability and Health Journal. 2008; 1(2):7988. [DOI:10.1016/j.dhjo.2008.01.001] [PMID]

[21] Green A. Reforming the health sector in Thailand: The role of policy actors on the policy stage. The International Journal of Health Planning and Management. 2000; 15(1):39-59. [DOI:10.1002/(SICI)1099-1751(200001/03)15:13.0.CO;2-9]

[22] Allison S, Nance M, Bastiampillai T, Hooper J, Roeger L, Goldney R. Health advocacy and the funding of mental health services reform. Australian and New Zealand Journal of Psychiatry. 2014; 48(9):802-4. [DOI:10.1177/0004867414546388] [PMID]

[23] Castle DJ. Where to for Australian mental health services? Promoting self-efficacy. Australian and New Zealand Journal of Psychiatry. 2013; 47(8):699-702. [DOI:10.1177/0004867413494484] [PMID]

[24] Richardson JR. Can we sustain health spending. Medical Journal of Australia. 2014; 200(11):629-31. [DOI:10.5694/ mja14.00564] [PMID]

[25] Whiteford $H$, Harris M, Diminic S. Mental health service system improvement: Translating evidence into policy. Australian and New Zealand Journal of Psychiatry. 2013; 47(8):703-6. [DOI:10.1177/0004867413494867] [PMID] 
[26] Iran MS Society. [Iran MS Society report (Persian)] [Internet] 2017. [Updated 2017 February 14]. Available from: http:// www.iranms.ir/.

[27] Field MJ, Jette AM, Institute of Medicine (US) Committee on Disability in America. The future of disability in America. In: National Academy of Sciences, editor. The National Academies Collection: Reports Funded by National Institutes of Health. Washington: National Academies Press; 2007.

[28] USA Today. Macron promotes Paris 2024 Olympic bid playing tennis. 2017 [Updated 2017 June 24]. Available from: https:// www.usatoday.com/story/sports/olympics/2017/06/24/ macron-promotes-paris-2024-olympic-bid-playing-tennis/103163112/

[29] Trust MCNF. A disability history timeline: The struggle for equal rights through the ages 2008. [Updated 2013 March 14] Available from: www.merseycare.nhs.uk/media/1749/disabiliyt-timeline-2013. 
This Page Intentionally Left Blank 